\title{
Chemical characteristics of ice residual nuclei in anvil cirrus clouds: evidence for homogeneous and heterogeneous ice formation
}

\author{
C. H. Twohy ${ }^{1}$ and M. R. Poellot ${ }^{2}$ \\ ${ }^{1}$ College of Oceanic and Atmospheric Sciences, Oregon State University, Corvallis, Oregon 97331-5503, USA \\ ${ }^{2}$ Dept. of Atmospheric Sciences, University of North Dakota, Grand Forks, North Dakota, 58202-9006, USA
}

Received: 31 March 2005 - Published in Atmos. Chem. Phys. Discuss.: 7 June 2005

Revised: 16 August 2005 - Accepted: 16 August 2005 - Published: 30 August 2005

\begin{abstract}
A counterflow virtual impactor was used to collect residual particles larger than about $0.1 \mu \mathrm{m}$ diameter from anvil cirrus clouds generated over Florida in the southern United States. A wide variety of particle types were found. About one-third of the nuclei were salts, with varying amounts of crustal material, industrial metals, carbonaceous particles, and sulfates. Ambient aerosol particles near the anvils were found to have similar compositions, indicating that anvils act to redistribute particles over large regions of the atmosphere. Sampling occurred at a range of altitudes spanning temperatures from -21 to $-56^{\circ} \mathrm{C}$. More insoluble (crustal and metallic) particles typical of heterogeneous ice nuclei were found in ice crystals at warmer temperatures, while more soluble salts and sulfates were present at cold temperatures. At temperatures below about -35 to $-40^{\circ} \mathrm{C}$, soluble nuclei outnumbered insoluble nuclei, evidently reflecting the transition from primarily heterogeneous to primarily homogeneous freezing as a source of anvil ice.
\end{abstract}

\section{Introduction}

Ice nucleation occurs in the atmosphere in two primary ways: through homogeneous freezing of liquid solution droplets and through heterogeneous interaction on a particulate nucleus. Homogeneous nucleation, or freezing, occurs at temperatures at or below about -35 to $-40^{\circ} \mathrm{C}$, while heterogeneous freezing may occur at much warmer temperatures. For both these processes, nucleating efficiency varies with temperature and supersaturation with respect to ice. Ice may also be formed by secondary processes such as rime splintering (Hallett and Mossop, 1974).

Homogeneous ice nucleation can be predicted by theory (Heymsfield and Miloshevich, 1995; Tabazadeh et al., 1997),

Correspondence to: C. H. Twohy

(twohy@coas.oregonstate.edu) while heterogeneous ice nucleation is much more complex. There are several mechanisms by which a heterogeneous ice nucleus may initiate ice formation, including deposition, contact, immersion, and condensation. It is generally accepted that heterogeneous ice nucleation occurs at specific sites on a nucleating particle and that favored ice nuclei are particles that have a lattice structure similar to ice. These processes, and particle types thought to be important for cirrus cloud formation, are summarized by DeMott (2002). Modeling studies have shown that the type and quantity of atmospheric aerosol particles acting as ice nuclei can influence ice cloud microphysical and radiative properties (Jensen et al., 2001; Gierens, 2003; Haag and Kärcher, 2004).

Ice nuclei have been studied in both the laboratory and the atmosphere. We briefly summarize atmospheric measurements applicable to convective and cirrus clouds here. Heintzenberg et al. (1996) and Twohy and Gandrud (1998) measured residual nuclei from cirrus and contrail ice, respectively, and found that mineral dust elements were common. In air traffic corridors, Petzold et al. (1998) found high concentrations of black carbon particles in both cirrus and contrails. Chen et al. (1998) found that mineral, carbonaceous and metallic particles all acted as heterogeneous ice nuclei, and DeMott et al. (2003a) determined that Saharan mineral dust had strong ice-nucleating activity. Flying at altitudes as high as $15 \mathrm{~km}$, Cziczo et al. (2004a) measured high concentrations of sulfates and sea-salt in ice residual nuclei, presumably from homogeneous freezing mechanisms. Sassen et al. (2003b) hypothesized that pristine crystal shapes detected in aged cirrus advected from a marine convective system may have been resulted from homogeneous freezing of sea-salt solution droplets. Cziczo et al. (2004b) and DeMott et al. (2003b) found that organic aerosols were less likely to partition to the ice phase than other particle types, and Kärcher and Koop (2005) show that differences in water uptake between organic and inorganic materials may cause this effect. 
Table 1. Particle classification scheme.

\begin{tabular}{ll}
\hline Category & Compositional signature \\
\hline Crustal dust & Silicates (rich in Si, variable $\mathrm{Na}, \mathrm{Mg}, \mathrm{Al}, \mathrm{K}, \mathrm{Ca}$, and Fe), carbonates (Mg and/or Ca with large C peak), phosphates (rare) \\
Soot & Carbon only. Characteristic morphology (chain aggregates) \\
Organic & Amorphous or irregular and may contain $\mathrm{O}, \mathrm{N}$, and $\mathrm{S}$, and $\mathrm{K}$ other than $\mathrm{C}$ \\
Sulfates & Sulfuric acid and ammonium sulfate/bisulfate. S, O only \\
Industrial & Metals such as $\mathrm{Al}, \mathrm{Fe}, \mathrm{Cr}, \mathrm{Ti}, \mathrm{Mn}, \mathrm{Co}, \mathrm{Zn}, \mathrm{Cu}$ \\
Salts & Chlorides and sulfates of $\mathrm{Na}, \mathrm{K}, \mathrm{Ca}$ and $\mathrm{Mg}$ \\
\hline
\end{tabular}

\section{Experiment}

The Cirrus Regional Study of Tropical Anvils and Cirrus Layers-Florida Area Cirrus Experiment (CRYSTAL-FACE; Jensen et al., 2004) was conducted in July 2002 in order to better understand anvil cirrus clouds. Several aircraft flew in anvils generated from thunderstorms that usually were located over the Florida landmass, at a latitude of about $26^{\circ} \mathrm{N}$. The particles described here were collected using the University of North Dakota Citation aircraft, which flew at cloud levels between about six and twelve $\mathrm{km}$, spanning environmental temperatures between -8 to $-56^{\circ} \mathrm{C}$. Particles from ambient clear air near the convection were sampled at generally lower altitudes, at temperatures between about +7 to $-32^{\circ} \mathrm{C}$.

Using a counterflow virtual impactor (CVI; Noone et al., 1988; Twohy et al., 1997), cirrus crystals larger than about $5 \mu \mathrm{m}$ diameter were virtually impacted into dry nitrogen where the water was removed through drying and heating of the sample stream to $50^{\circ} \mathrm{C}$. Non-volatile residual nuclei were then impacted onto carbon-coated nickel electron microscope grids using a two-stage jet impactor. The 50\% cut sizes of the two impactor stages were about 0.56 and $0.10 \mu \mathrm{m}$ diameter for unit density spherical particles or 0.38 and $0.07 \mu \mathrm{m}$ diameter for $1.7 \mathrm{~g} \mathrm{~cm}^{-3}$ density particles at typical sampling pressures of $350 \mathrm{mb}$. Particles from these two stages will hereafter be called the "large" and "small" stage samples, respectively. (Note that we often refer to what is sampled as "residual nuclei" here, although actually material may also be incorporated from cloud processes besides nucleation, such as coagulation or chemical reactions). Several ambient aerosol samples from near and below the anvil were collected by turning off the counterflow, so that the CVI acted as a simple aerosol inlet. Samples were then sized and analyzed using a Phillips CM-12 analytical transmission electron microscope, with energy dispersive X-ray spectroscopy for information on elemental composition. The X-ray energy detector installed on the instrument has a Quantum ${ }^{\mathrm{TM}}$ thin window that allows detection of elements heavier than atomic number 5 . Non-volatile particles were classified into different particle types based on the scheme shown in Table 1 , using actual X-ray signatures from every particle rather than relying on morphology alone to identify particle types.
When sampling ice clouds with different inlets, Murphy et al. (2004) and Kojima et al. (2004) found high concentrations of particles containing stainless steel and zinc, respectively, that may have been produced when ice crystals abraded their inlet surfaces. Metallic particles would be included in our "industrial" category. Since the CVI inlet used in this study was composed of stainless steel, particles with this composition must be viewed as possible artifacts. We examined our data for particles with stainless steel composition using iron and chromium as tracers (nickel could not be positively identified since the collection grids were made of nickel). Only $1 \%$ of the small residual nuclei and $2 \%$ of the large residual nuclei were composed of just these elements. These elements were sometimes mixed with substantial amounts of other metallic elements, however, with these mixtures comprising $4 \%$ of the small nuclei number and $11 \%$ of the large nuclei number. The sources of these mixed particles are unknown, but it is difficult to envision a scenario in which they could be produced from the CVI inlet itself. Since the percentage of wholly stainless steel particles was very small and it is likely that the mixed metallic particles would, in fact, be good ice nuclei, we do not believe that contamination by stainless steel was significant for this study.

An additional possible sampling issue is that large ice crystals may break upon striking inlet surfaces or due to wind shear, producing multiple crystals for each original crystal (Field et al., 2003; Korolev and Isaac, 2005). Assuming that an ice crystal has only one nucleus, this should not in general produce additional residual nuclei. However, material could have been added to the crystal through other processes such as scavenging. This material has the potential to produce additional small particles when crystals break up and sublimate. Apparent enhancement in fine particles larger than about $20 \mathrm{~nm}$ (as measured by a condensation nucleus counter; Zhang and Liu, 1991) was often observed when large ice crystals are present. Seifert et al. (2003) argued, however, that the amount of material potentially added to cirrus crystals by scavenging is small, due to the low concentrations of ice crystals and interstitial aerosol in typical cirrus. Also, the time available for large ice crystals (the ones most likely to shatter) to scavenge interstitial particles is relatively short due to their high sedimentation rates (Jensen et al., 1996). 
In order to address the possibility that crystal breakup or other sampling issues, such as volatile losses, were causing an enhancement or depletion of residual nuclei, the number of residual particles detected through collection and analysis on the microscope grids was estimated as follows. For a selected sample subset, all particles in a 45 degree wedge corresponding to $1 / 8$ of the total grid area were subjected to a visual count. This value was then multiplied by 8 to estimate the total number of particles on the visible area of each grid, and then corrected for the portion of each grid covered by solid grid material (on which particles cannot be observed). Finally, the sample volume and CVI enhancement factor were used to determine the effective ambient concentration of particles collected on each grid. Then, the small and large stage concentrations were totaled. We recognize that this is an imperfect method to determine particle number; the distribution of particles collected by impactors is not uniform and particles are concentrated in a region just below the jet, which may not be precisely in the center of the sampling grid. Since this is a random error, however, it should be minimized when numerous samples are analyzed. Additionally, the particle loading was light enough that particles were not piled on top of each other, so individual particles could always be discerned.

Figure 1 shows the result of this analysis for seven pairs of samples. Concentrations measured by the Forward Scattering Spectrometer Probe (FSSP-100, size range 3-54 $\mu \mathrm{m}$ diameter) and Particle Measuring Systems 2D-C probe (size range 30-2800 $\mu \mathrm{m}$ diameter) during the sampling periods are also given for comparison. Since the $2 \mathrm{D}-\mathrm{C}$ probe only measures the larger ice crystals, it is expected to have the lowest values. The FSSP and CVI measure similar crystal size ranges and so should have similar values, but the FSSP values are up to an order of magnitude higher. The FSSP is known to overestimate number concentration in the presence of irregularly shaped ice crystals, such as are present in anvil cirrus (Gayet et al., 1996; Field et al., 2003). While the magnitude of this effect is not well understood and varies with crystal type and size distribution, it can be up to an order or magnitude, the value used to apply error bars to Fig. 1. Uncertainty in the concentration of CVI residuals is estimated at 50\% (random error due to counting only a portion of the grid), while the 2D-C is known to undercount crystals (Korolev et al., 1998) and its bias is estimated at $100 \%$. Given the large uncertainties, it is difficult to make firm conclusions from this analysis, but there is no strong evidence that CVI number concentrations are significantly larger or smaller than expected based on the other instruments. Better measurements of the small ice crystal number concentrations are of great importance to narrow this uncertainty in future work.

Noone et al. (1993), Ström et al. (1997), and Seifert et al. (2003) reported that a large fraction of nuclei in in-situ generated cirrus clouds were smaller than about $0.1 \mu \mathrm{m}$ in diameter. Since most of the particle types sampled in this project should have densities of at least $1.7 \mathrm{~g} \mathrm{~cm}^{-3}$, particles

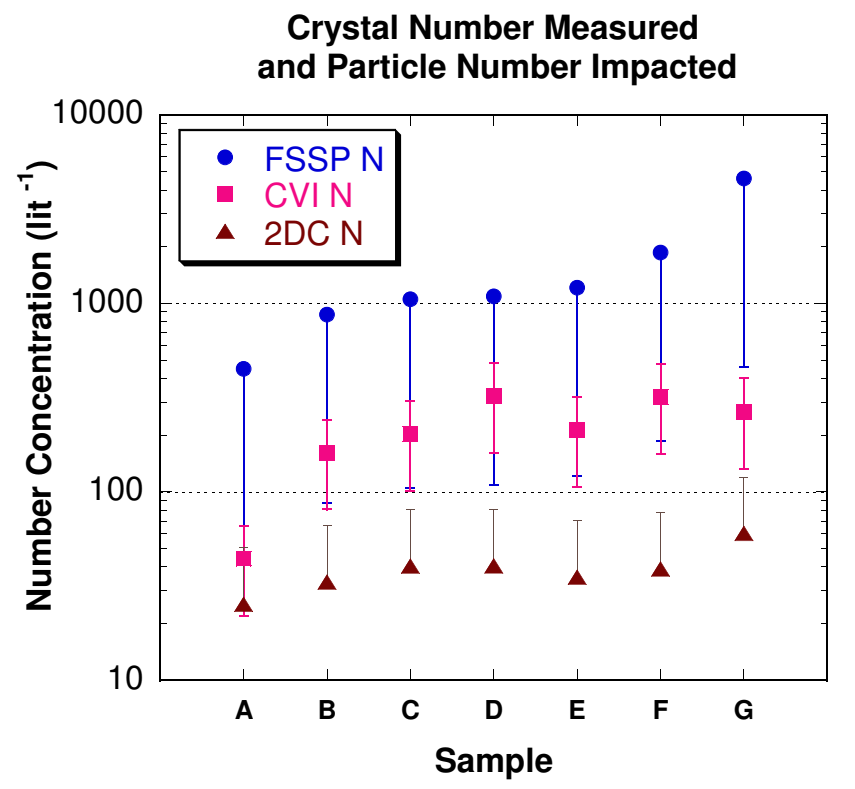

Fig. 1. Equivalent number concentration of particles collected on CVI electron microscope grids compared to number measured by the FSSP-100 and 2D-C probes for seven different samples. Error bars represent measurement uncertainty as described in the text. Due to the lengthy time required to perform the count, only seven of the total microscope samples were analyzed.

down to about $0.07 \mu \mathrm{m}$ should have been sampled on the second stage of the impactor used. However, less than $2 \%$ of all particles analyzed were observed to be smaller than $0.10 \mu \mathrm{m}$, even after applying corrections for spreading on the sampling substrate (McInnes et al., 1997). Undercounting of some small particles may have occurred due to the tendency to choose larger particles that are more visible to the human eye, and small volatile organic particles may have been vaporized by the vacuum environment and/or the electron beam of the electron microscope. Therefore, the data presented here effectively apply only to residual particles about $0.10 \mu \mathrm{m}$ and larger in diameter.

\section{Results}

\subsection{Percentages of chemical types observed}

Data from ten flights on nine different days are presented. Sampling times ranged from four to twenty-seven minutes. Fourteen cloud residual samples and four ambient samples were analyzed. Of the fourteen cloud samples, both large and small stage samples were analyzed for ten of them. Fifty particles were examined from each impactor stage, except for two samples in which fewer numbers (25 and 40) were analyzed due to extremely low sample loading. The total number of particles analyzed was 1115 (cloud residuals) and 400 (ambient). In-cloud temperatures ranged from -8 to $-56^{\circ} \mathrm{C}$. 

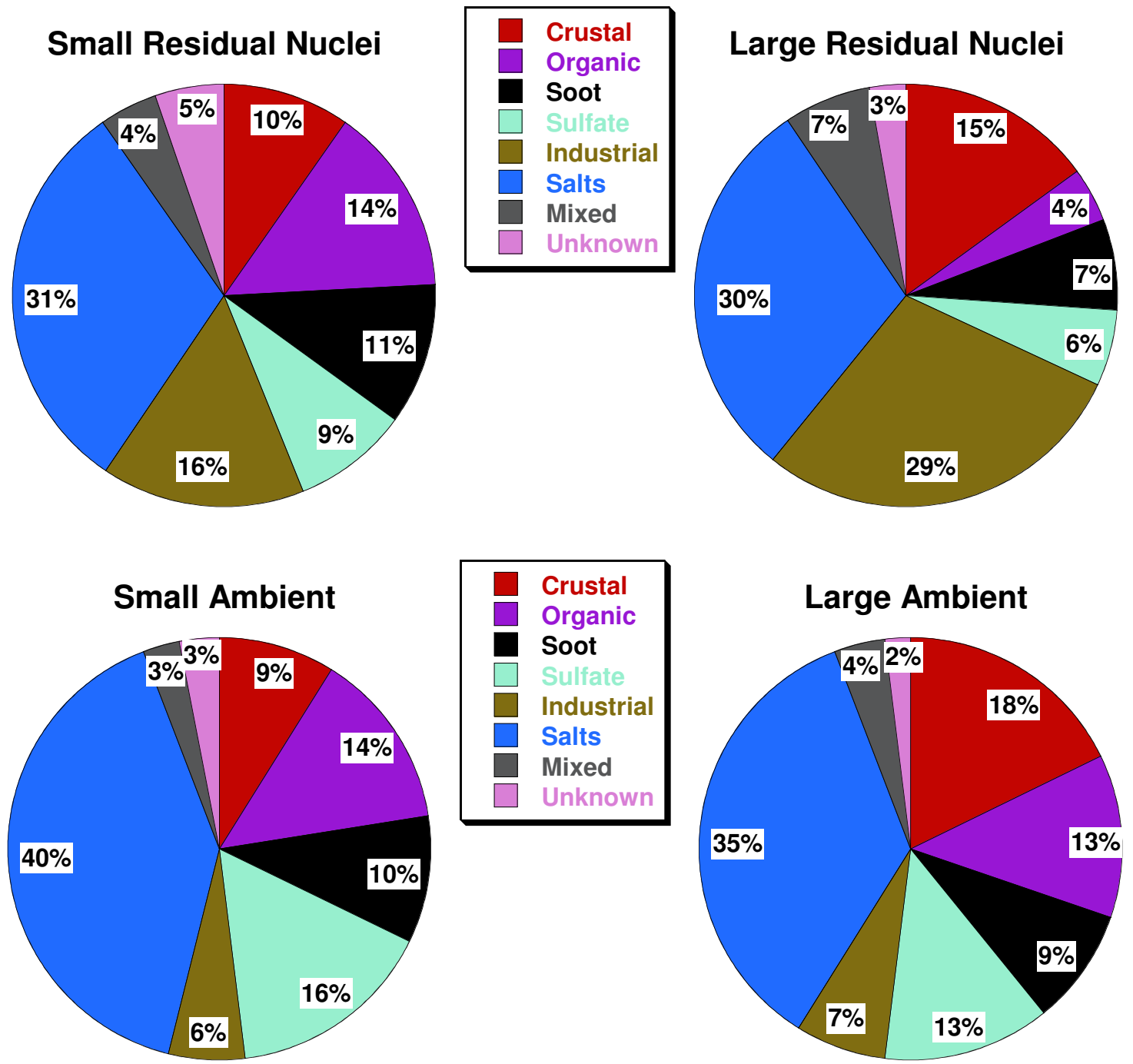

Fig. 2. The average composition of small and large residual ice nuclei (top left and right) and small and large ambient particles (bottom left and right) collected during CRYSTAL-FACE. Values are percent by number of each composition as determined by X-ray analysis and the categorization scheme in Table 1 . Data from a primarily liquid cloud has not been included.

The warmest case was a predominately liquid cloud, while the other cases at $-21>\mathrm{T}>-56^{\circ} \mathrm{C}$ were anvil ice clouds.

Figure 2 shows the average composition of residual nuclei for small and large stage particles and for ambient samples collected nearby. The liquid cloud sample has not been included in this summary, but is discussed later. Many different particle types are present in both the anvil nuclei and the ambient aerosol particles. The most prominent feature in the data from all particle categories is that about a third of the particles are composed of salts. Sodium, potassium, and calcium salts, most containing sulfur, were all present in substantial amounts. These particles (with the possible exception of calcium sulfate) are not traditional heterogeneous ice nuclei and are expected to act as condensation nuclei for liquid droplets instead. This indicates that a large fraction of anvil ice is produced by homogeneous freezing mechanisms at the cold temperatures in the upper portions of these deep convective clouds. Cziczo et al. (2004a) also found large quantities of salts in anvil ice and these combined results suggest that salts may be a more important source of homogeneous freezing nuclei than was previously recognized. The sulfate category may be combined with the salt category to show that $36-40 \%$ of the non-volatile residual nuclei above about $0.10 \mu \mathrm{m}$ are composed of soluble material. Mass spectrometric techniques have revealed that many sulfate particles in the atmosphere actually are mixed with carbonaceous material (Murphy et al., 1998; Guazzotti et al., 2001). Small amounts of carbon are difficult to detect by the X-ray techniques employed here, but some of the salts did contain detectable amounts of carbon, particularly the potassium salts. These potassium-containing particles were likely derived from biomass burning, and were introduced 
into the Florida area via long-range transport at high altitude from fires in the United States and Canada (Hudson et al., 2004; Jost et al., 2004).

The next most prominent particle types are insoluble materials generated from soil (crustal dust) and industry. (Note that our "industrial" category includes only metals and not other substances that might be produced by industry but also have other sources, such as sulfates and organics). These insoluble materials, which are mechanically produced and more prevalent in the large particle mode, are known to be good heterogeneous ice nuclei. Saharan dust was prevalent in the Florida region during much of the CRYSTAL-FACE sampling period (Sassen et al., 2003a). Insoluble particles account for approximately $26-44 \%$ of all residual nuclei, and they are enhanced in the large particle mode.

Eleven to $25 \%$ of the residual nuclei are composed of carbonaceous material, both soot (black carbon) and organic carbon. These particles are more numerous in the small particle size range. Whether these particles entered the clouds through nucleation scavenging or through in-cloud scavenging and whether they encourage or inhibit ice crystal formation is an open area of research. As discussed earlier, some organic species inhibit ice formation, while others can act as cloud condensation nuclei (Novakov and Corrigan, 1996; Raymond and Pandis, 2002) and form droplets that would later freeze. Soot has been shown to be involved in ice nucleation (DeMott, 1990), but its behavior is more complex than that of other heterogeneous ice nuclei. It is not surprising that many different particle types serve as sites for condensation at the high supersaturations (Heymsfield et al., 2005) produced in these vigorous convective clouds.

The remaining 9-10\% of residual nuclei are composed of mixed particles (often crustal or industrial with salts) or particles that could not be categorized. The mixed category could be caused by in-cloud coagulation or aggregation, and may have important activity as heterogeneous ice nuclei (Zuberi et al., 2002). The unknown category is most likely comprised of carbonaceous material. Carbon sometimes cannot be detected from particles too close to sample grid edges or from those that volatilize rapidly under the electron beam. Our results for residual nuclei are qualitatively similar to those of Cziczo et al. (2004a) for the Florida area, although they analyzed fewer residual nuclei and those from primarily the small ice crystals.

The relatively small difference between ambient and cloud nuclei composition shown in Fig. 2 is somewhat surprising. Ambient measurements made by the Citation were typically very near the convective cells or under the anvil itself. The composition of the ambient samples in this region is quite different from that of ambient upper tropospheric particles well removed from convection (Chen et al., 1998; Twohy et al., 2002; Cziczo et al., 2004a), which are primarily sulfates and organics. This indicates that clouds are not only particle sinks at low altitude, but can act as significant sources of particles at mid and high altitudes as well. This could be especially important in the case of deep convective clouds, which carry particles to high altitudes and which have large anvils. In the anvil, particles are spread out over an extensive horizontal range and can be efficiently redistributed vertically through sedimentation. Particles generated at the surface such as sea-salt, soil-dust and industrial emissions are physically and chemically different from the sulfates and organics typically found in the upper troposphere. This infusion of nucleating agents of different types into the upper troposphere is expected to influence ice crystal number, size and shape (Sassen et al., 2003b) and therefore the radiative properties of clouds formed subsequently. This redistribution of low and mid-level particles is different from another important role of convection, the transport of low-level gaseous species to the upper troposphere where they can transform and create new ultrafine particles (e.g., Clarke, 1993; Twohy et al., 2002).

Fridlind et al. (2004) used a large-eddy simulation model of one of the CRYSTAL-FACE cases to predict that most of the ice produced in the thunderstorm convective core nucleates not on below-cloud aerosol particles, but on particles entrained from the side of the clouds in the mid-troposphere. We estimate that about $2 / 3$ of the salts measured with the CVI were either sodium or calcium salts originating at low altitudes. Assuming that all the industrial particles also had surface sources, about $37 \%$ of the small residual nuclei and $49 \%$ of the large nuclei sampled in this study were from low altitudes. Crustal material (if Saharan dust), potassium salts and soot from aircraft or long-range transport are expected to enter the clouds at higher levels, and these categories comprise $31-32 \%$ of the small and the large nuclei. (The remaining major categories, sulfates and organics, could come from a variety of altitudes, as they were present both in boundary layer sampling (Conant et al., 2004) and at high altitudes (Cziczo et al., 2004a)). These results suggest a higher dependence of anvil ice formation on boundary layer aerosol particles than predicted by Fridlind et al. (2004). However, Yin et al. (2005) used a detailed microphysical model to show that many boundary layer aerosols are transported to higher altitudes by convection, detrained, and then re-entrained and activated again. This detrainment/entrainment cycle could explain both the high proportion of boundary layer aerosols we measured in the ambient air at mid-altitudes near the convection, as well as the high proportion found in anvil ice.

\subsection{Temperature dependence and freezing mechanism}

Figure 2 showed average results for all samples, but there was a substantial variation in nuclei composition between samples, which were collected at a range of environmental temperatures and altitudes. Anvil ice may be produced through heterogeneous nucleation on solid nuclei (crustal or industrial/metallic particles) or through homogeneous freezing of dilute solutions (salt or sulfate droplets). Since these nucleation processes are expected to occur at different 


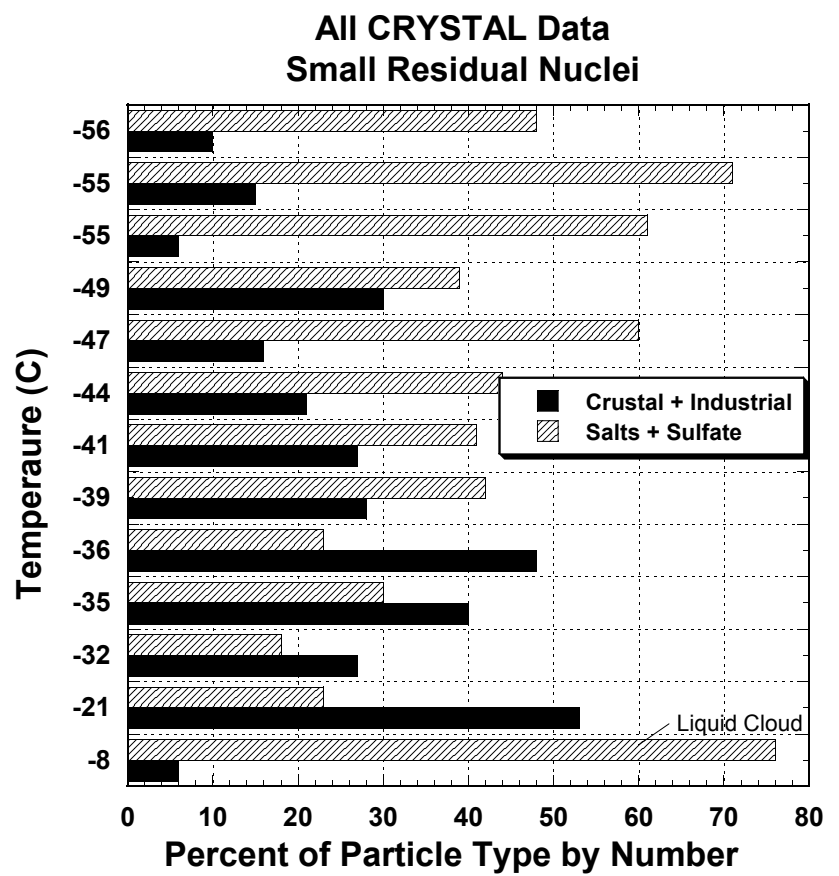

Fig. 3. Percentages of [crustal+industrial] and [salts+sulfate] particles relative to total number of residual nuclei collected in anvil cirrus as a function of environmental temperature. The cloud at $-8^{\circ} \mathrm{C}$ was predominately liquid, and thus has a high percentage of soluble residual material.

temperatures, a dependence of nuclei composition on nucleating temperature would be expected. Our sampling occurred at the current environmental temperature, however, and not necessarily the temperature at which the ice nucleated. While we expect that the two temperatures are related, evolution of the cloud and anvil may result in movement of ice to different temperature regions after nucleation. These changes could possibly be investigated using radar data or detailed modeling simulations, which are beyond the scope of this study. Here the data are used to see if a dependence of residual nuclei composition on sampling temperature can still be detected. For this analysis, the crustal and industrial particles were grouped together and the salts and sulfates were grouped together, since these groups are expected to have very different freezing mechanisms. Particle types whose nucleating tendencies are less clear (organics, soot, mixed, and unknown) were excluded from the analysis.

In Fig. 3, the percentages of residual nuclei types in the soluble and insoluble groups are shown as a function of average ambient temperature during each sampling period. The smaller residual nuclei, for which more samples were available, are shown. A very interesting pattern emerges moving from the coldest temperatures at the top of the plot, where soluble particle types dominate, to warmer temperatures, where insoluble ones dominate. The sample at $-8^{\circ} \mathrm{C}$ is an exception, as this was a predominately liquid (super-
Table 2. Sample dates and times.

\begin{tabular}{ccccc}
\hline $\begin{array}{c}\text { Flight \& } \\
\text { Sample\# }\end{array}$ & Date & Time & Temperature & Sample Type \\
\hline $1-1$ & 3 July 02 & $19: 06-19: 13$ & -21 & Ice Cloud \\
$3-1$ & 9 July 02 & $18: 15-18: 20$ & -18 & Ambient \\
$3-2$ & 9 July 02 & $21: 05-21: 12$ & -47 & Ice Cloud \\
$4-1$ & 11 July 02 & $15: 11-15: 26$ & -8 & Liquid Cloud \\
$4-2$ & 11 July 02 & $16: 01-16: 10$ & -32 & Ambient \\
$5-1$ & 11 July 02 & $19: 26-19: 32$ & -35 & Ice Cloud \\
$5-2$ & 11 July 02 & $19: 57-20: 07$ & -39 & Ice Cloud \\
$5-3$ & 11 July 02 & $20: 14-20: 30$ & -49 & Ice Cloud \\
$5-4$ & 11 July 02 & $20: 36-21: 01$ & -55 & Ice Cloud \\
$6-3$ & 16 July 02 & $22: 33-22: 37$ & -18 & Ambient \\
$9-2$ & 21 July 02 & $21: 56-22: 23$ & -55 & Ice Cloud \\
$10-1$ & 23 July 02 & $21: 26-21: 39$ & -32 & Ice Cloud \\
$10-2$ & 23 July 02 & $22: 06-22: 16$ & -56 & Ice Cloud \\
$11-1$ & 25 July 02 & $16: 00-16: 17$ & -44 & Ice Cloud \\
$11-2$ & 25 July 02 & $16: 43-16: 50$ & -41 & Ice Cloud \\
$11-4$ & 25 July 02 & $18: 48-19: 12$ & -36 & Ice Cloud \\
$12-1$ & 26 July 02 & $23: 26-23: 38$ & +7 & Ambient \\
$14-1$ & 29 July 02 & $18: 55-19: 08$ & -41 & Ice Cloud \\
\hline
\end{tabular}

cooled) cloud with only small amounts of ice. Water droplets in a liquid cloud will form preferentially on soluble particle types, and this case is included as an interesting contrast to the others.

Note that the percentages in Fig. 3 don't add to 100, as only a subset of all particle types shown in Fig. 2 are included. The relationship between soluble and insoluble nuclei can be more clearly examined by plotting their ratio. This effectively normalizes the soluble and insoluble values and eliminates the effect of the other, less well understood, particle types on the comparison. In Fig. 4 this ratio, R, is plotted as a function of environmental temperature for both the large and small residual nuclei. Also included for reference are the flight and sample numbers, which may be referenced in Table 2.

For the large residual nuclei (left panel of Fig. 4), $\mathrm{R}$ is only about 0.05 at the warmest temperature, suggesting that nearly all large nuclei involved in heterogeneous ice formation are insoluble. At temperatures below about $-35^{\circ} \mathrm{C}, \mathrm{R}$ for large nuclei is near one. For small nuclei (right panel of Fig. 4), $\mathrm{R}$ is less than one for temperatures warmer than about $-35^{\circ} \mathrm{C}$ (with the exception of the outlying case discussed earlier) and larger than one for temperatures colder than about $-35^{\circ} \mathrm{C}$. This suggests that soluble nuclei become increasingly important in ice formation at this temperature. Using microphysical data, Heymsfield et al. (2005) discuss the importance of this -35 to $-40^{\circ} \mathrm{C}$ temperature range, where homogeneous freezing of cloud droplets a few microns in size begins to occur. DeMott et al. (2003b) used a continuous flow diffusion chamber to show that large amounts of ice are nucleated homogeneously at these temperatures. Despite 

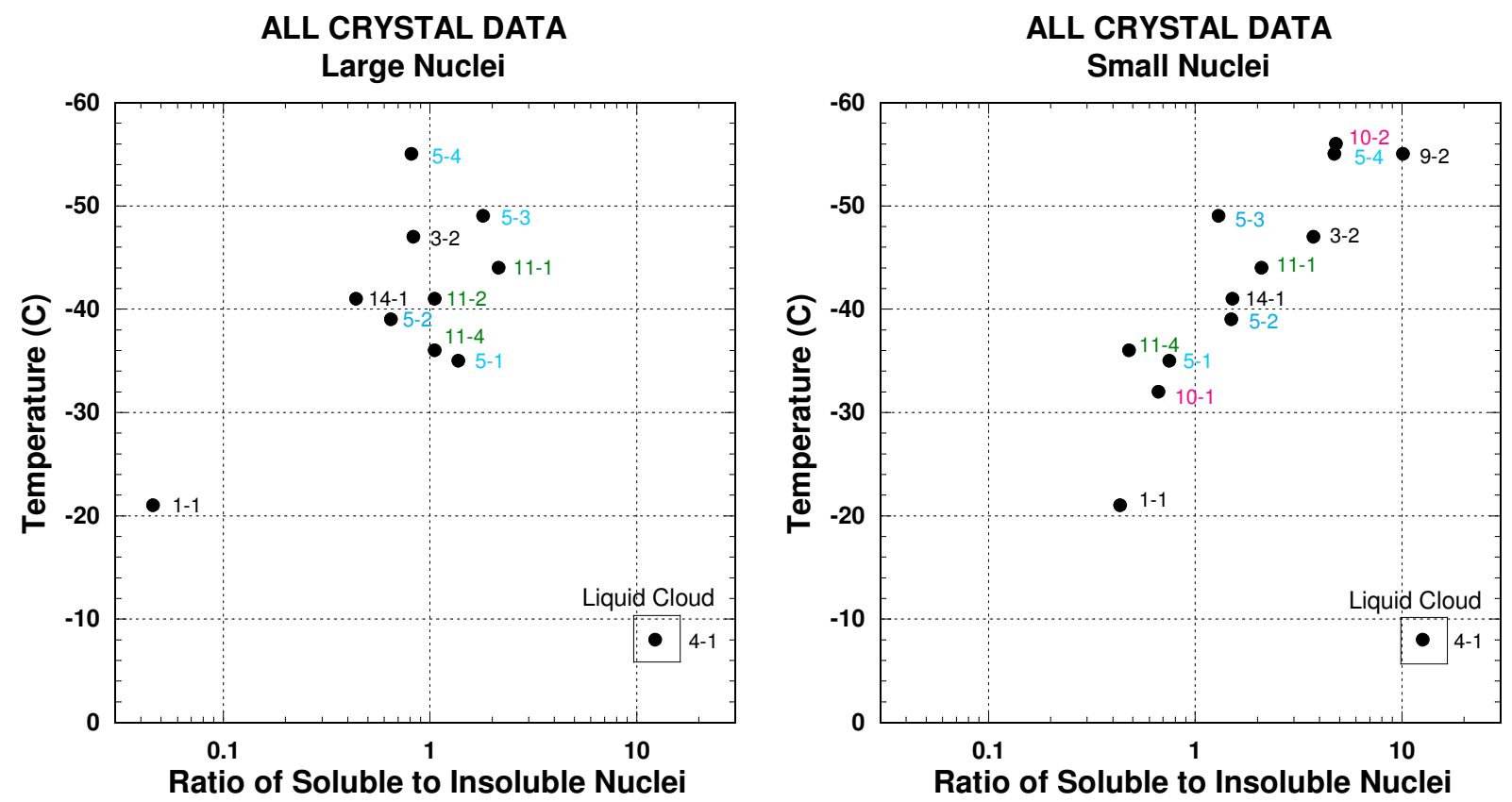

Fig. 4. Ratio, R, of soluble (salts and sulfates) to insoluble (crustal and industrial) residual nuclei as a function of anvil environmental temperature for all CRYSTAL-FACE CVI samples. Left plot shows results for large nuclei and right plot for smaller nuclei. Numbers to the right of each data point refer to flight and sample numbers as given in Table 2.

possible differences between our sampling temperature and the actual nucleation temperature, these data still show an apparent transition between the heterogeneous and homogeneous freezing regime.

The reason that the soluble/insoluble ratio is not greater at low temperatures for large nuclei is probably the lack of large soluble particles at these altitudes. Few large soluble particles from the surface are expected to reach and survive at the highest altitudes, since they are the best cloud condensation nuclei, form the largest droplets, and are most likely to be removed from the clouds in precipitation from deep convection (Ekman et al., 2004). R for small nuclei increases with decreasing temperature up to a ratio as high as ten at the coldest temperatures. There are two possible explanations for this phenomenon. First, below $-40^{\circ} \mathrm{C}$, even small haze droplets $(<1 \mu \mathrm{m})$ will freeze. If these particles are entrained into the cloud at high altitudes, additional small ice crystals will be produced on soluble nuclei. However, Fridlind et al. (2004) and Heymsfield et al. (2005) argue that most of the entrainment occurs at mid-cloud levels and that most of the ice crystal number are produced between about $-35^{\circ} \mathrm{C}$ and $-40^{\circ} \mathrm{C}$, and then lofted to higher altitudes. If this is the case, the ratio of soluble to insoluble nuclei is expected to be large at all temperatures colder than $-40^{\circ} \mathrm{C}$ in the convective core. Once the anvil forms, however, several processes can act to reduce $\mathrm{R}$.

First, dilution and evaporation in the anvil region will preferentially remove the smallest ice crystals, which nucleate on the smallest soluble nuclei. This will reduce $\mathrm{R}$ values. Sec- ond, aggregation will combine a few large ice crystals with many small ones. The largest crystals will be those that nucleated heterogeneously on insoluble nuclei. This process will deplete soluble nuclei and will further reduce $\mathrm{R}$ values. Finally, sedimentation will preferentially move large ice crystals with insoluble nuclei to lower altitudes and warmer temperatures, while the surviving small crystals with soluble nuclei will remain near cloud top. This could produce the trend of increasing $\mathrm{R}$ with decreasing temperature exhibited in the right panel of Fig. 4.

\section{Summary and conclusions}

Non-volatile residual particles (>about $0.10 \mu \mathrm{m}$ ) from ice crystals in fourteen Florida anvil samples were shown to be composed of a variety of particle types, including salts, metals (industrial), crustal dust, soot, sulfate and organics. In general, larger nuclei had more industrial and crustal material, while smaller nuclei had more organics and soot. The composition of ambient aerosol near and below the anvils was similar to that in the anvil, but was very different from that in the upper troposphere in other regions not influenced by convection. In particular, large numbers of salt particles were present in the near-convective region. This indicates that convection can add to the variability and diversity of aerosol composition in the upper troposphere and likely influence subsequent cloud formation. 
Convection subjects particles to a wide variety of temperatures within a single cloud system, and the type and frequency of ice crystal nucleation is strongly influenced by temperature. Our data, taken at a range of environmental temperatures, reflect the influence of these different nucleation mechanisms. In particular, -35 to $-40^{\circ} \mathrm{C}$ is a transition region between heterogeneous freezing processes on solid nuclei and homogeneous freezing on solution droplets. The ratio of soluble (salts and sulfates) to insoluble (metals and crustal) nuclei increases from low values to more than one at temperatures below -35 to $-40^{\circ} \mathrm{C}$. At the coldest temperatures, small soluble nuclei were up to ten times more numerous than insoluble ones. The variation in $\mathrm{R}$ with height at cold temperatures probably reflects the evaporation, aggregation, and sedimentation processes that occur in the anvil.

Deep convection and associated anvils influence large regions of the upper troposphere and stratosphere in much of the tropics and mid-latitudes. Anvils are important not only due to their influence on the radiative properties of the atmosphere, but for their role in distributing particles and gases from narrow regions of the lower troposphere to wide regions of the upper troposphere. As modeling studies have shown, the type and location of available ice nuclei will influence the amount and size of ice crystals formed. This, in turn, influences the evaporation and sedimentation rate and thus the vertical and horizontal distance over which nuclei are redistributed upon evaporation. Both measurements and modeling studies are needed to fully describe these processes. In addition, continuing laboratory studies are required to further understand the ice nucleating properties of organic and soot carbon, which are prevalent in most parts of the atmosphere.

Acknowledgements. This work was supported by NASA Code Y Radiation Sciences Program. J. Vanegas performed much of the electron microscopy at Oregon State University. P. DeMott at Colorado State University and A. Fridlind at NASA provided insightful comments. Thanks also to P. Buseck, T. Kojima, and J. Anderson at Arizona State University for helpful discussions regarding classification schemes for electron microscopy. A. Heymsfield at NCAR helped develop various aspects of the project and provided inspiration.

Edited by: U. Lohmann

\section{References}

Chen, Y., Kreidenweis, S. M., McInnes, L. M., Rogers, D. C., and DeMott, P. J.: Single particle analyses of ice nucleating aerosols in the upper troposphere and lower stratosphere, Geophys. Res. Lett., 25, 1391-1394, 1998.

Clarke, A. D.: Atmospheric nuclei in the pacific midtroposphere: their nature, concentration, and evolution, J. Geophys. Res., 98, $20633-20647,1993$.

Conant, W. C., VanReken, T. M., Rissman, T. A., Varutbangkul, V., Jonsson, H. H., Nenes, A., Jimenez, J. L., Delia, A. E., Bahreini, R., Roberts, G. C., Flagan, R. C., and Seinfeld, J. H.: Aerosol- cloud drop concentration closure in warm cumulus, J. Geophys. Res. 109, D13204, doi:10.1029/2003JD004324, 2004.

Cziczo, D. J., Murphy, D. M., Hudson, P. K., and Thomson, D. S.: Single particle measurements of the chemical composition of cirrus ice residue during CRYSTAL-FACE, J. Geophys. Res., 109, D04201, doi:10.1029/2003JD004032, 2004a.

Cziczo, D. J., DeMott, P. J., Brooks, S. D., Prenni, A. J., Thomson, D. S., Baumgardner, D., Wilson, J. C., Kreidenweis, S. M., and Murphy, D. M.: Observations of organic species and atmospheric ice formation, Geophys. Res. Lett., 31, L12116, doi:10.1029/2004GL019822, 2004b.

DeMott, P. J.: An exploratory study of ice nucleation by soot aerosols, J. Appl. Meteor., 29, 1072-1079, 1990.

DeMott, P. J.: Laboratory studies of cirrus cloud processes, Chapter 5 , in: Cirrus, edited by: Lynch, D. K., Sassen, K., Starr, D. O'C., Stephens, G., Oxford University Press, New York, 102135, 2002.

DeMott, P. J., Sassen, K., Poellot, M. R., Baumgardner, D., Rogers, D. C., Brooks, S. D., Prenni, A. J., and Kreidenweis, S. M.: African dust aerosols as atmospheric ice nuclei, Geophys. Res. Lett., 30, doi:10.1029/2003GL017410, 2003a.

DeMott, P. J., Cziczo, D. J., Prenni, A. J., Murphy, D. M., Kreidenweis, S. M., Thomson, D. S., Borys, R., and Rogers, D. C.: Measurements of the concentration and composition of nuclei for cirrus formation, Proc. Natl. Acad. Sci., 100, 14 655-14 660, 2003 b.

Ekman, A. M. L., Wang, C., Wilson, J., and Ström, J.: Explicit simulations of aerosol physics in a cloud-resolving model: a sensitivity study based on an observed convective cloud, Atmos. Chem. Phys., 4, 773-791, 2004,

SRef-ID: 1680-7324/acp/2004-4-773.

Field, P. R., Wood, R., Brown, P. R. A., Kaye, P. H., Hirst, E., Greenaway, R., and Smith, J. A.: Ice particle interarrival times measured with a fast FSSP, J. Atmos. Oceanic Technol., 20, 249261, 2003.

Fridlind, A. M., Ackerman, A. S., Jensen, E. J., et al.: Evidence for the predominance of mid-tropospheric aerosols as subtropical anvil cloud nuclei, Science, 304, 718-722, 2004.

Gayet, J.-F., Febvre, G., and Larsen, H.: The reliability of the PMS FSSP in the presence of small ice crystals, J. Atmos. Ocean. Technol., 13, 1300-1310, 1996.

Gierens, K.: On the transition between heterogeneous and homogeneous freezing, Atmos. Chem. Phys., 3, 437-446, 2003, SRef-ID: 1680-7324/acp/2003-3-437.

Guazzotti, S. A., Coffee, K. R., and Prather, K. A.: Continuous measurements of size-resolved particle chemistry during INDOEXIntensive Field Phase 99, J. Geophys. Res., 106, D22, $28607-$ 28627, 2001.

Haag, W. and Kärcher, B.: The impact of aerosols and gravity waves on cirrus clouds at midlatitudes, J. Geophys. Res., 109, D12202, doi:10.129/2004JD004579, 2004.

Hallett, J. and Mossop, S. C.: Production of secondary ice crystals during the riming process, Nature, 249, 26-28, 1974.

Heintzenberg, J., Okada, K., and Ström, J.: On the composition of non-volatile material in upper tropospheric aerosols and cirrus crystals, Atmos. Res., 41, 81-88, 1996.

Heymsfield, A. J. and Miloshevich, L. M.: Relative humidity and temperature influences on cirrus formation and evolution: Observations from Wave Clouds and FIRE II., J. Atmos. Sci., 52, 
4302-4326, 1995.

Heymsfield, A. J., Miloshevich, L. M., Schmitt, C., Bansemer, A., Twohy, C. Poellot, M. R., Fridland, A., and Gerber, H.: Homogeneous ice nucleation in tropical convection and its influence on cirrus anvil microphysics, J. Atmos. Sci, 62, 41-64, 2005.

Hudson, P. K., Murphy, D. M., Cziczo, D. J., Thomson, D. S., De Gouw, J. A., Warneke, C. Holloway, J., Jost, H-J., and Hübler, G.: Biomass-burning particle measurements: Characteristic composition and chemical processing, J. Geophys. Res., 109, doi:10.1029/2003JD004398, 2004.

Jensen, E. J., Toon, O. B., Selkirk, H. B., Spinhirne, J. D., and Schoeberl, M. R.: On the formation and persistence of subvisible cirrus near the tropical tropopause, J. Geophys. Res., 101, $21361-21375,1996$.

Jensen, E. J., Toon, O. B., Vay, S. A., Ovarlez, J., May, R., Bui, P., Twohy, C. H., Gandrud, B. W., Pueschel, R. F., and Schumann, U.: Prevalence of ice supersaturated regions in the upper troposphere: implications for optically thin ice cloud formation, J. Geophys. Res., 106, 17 253-17 266, 2001.

Jensen, E., Starr, D., and Toon, O. B.: Mission investigates tropical cirrus clouds, EOS, 85, 45-50, 2004.

Jost, H.-J., Drdla, K., Stohl, K., et al.: In-situ observations of midlatitude forest fire plumes deep in the stratosphere, Geophys. Res. Lett., doi:10.1029/2003GL019253, 2004.

Kärcher, B. and Koop, T.: The role of organic aerosols in homogeneous ice formation, Atmos. Chem. Phys., 5, 703-714, 2005, SRef-ID: 1680-7324/acp/2005-5-703.

Kojima, T., Buseck, P. R., Wilson, J. C., Reeves, J. M., and Mahoney, M. J.: Aerosol particles from tropical convective systems: Cloud tops and cirrus anvils, J. Geophys. Res., 109, D12201, doi:10.1029/2003JD004504, 2004.

Korolev, A., Strapp, J. W., and Isaac, G. A.: Evaluation of the Accuracy of PMS Optical Array Probes, J. Atmos. Oceanic Technol., 15, 708-720, 1998.

Korolev, A. and Isaac, G. A.: Shattering during sampling by OAPs and HVPS, Part 1: Snow particles, J. Atmos. Oceanic Technol., 22, 528-542, 2005.

McInnes, L. M., Covert, D. S., Quinn, P. K., and Germani, M. S.: Measurement of chloride depletion and sulfur enrichment in individual sea-salt particles collected from the remote marine boundary layer, Tellus, 49B, 300-319, 1997.

Murphy, D. M., Thompson, D. S., and Mahoney, M. J.: In Situ Measurements of organics, meteoritic material, mercury, and other elements in aerosols at 5 to 19 kilometers, Science, 282, 16641669, 1998.

Murphy, D. M., Cziczo, D. J., Hudson, P. K. Thomson, D. S., Wilson, J. C., Kojima T., and Buseck, P. R.: Particle generation and resuspension in aircraft inlets when flying in clouds, Aerosol Sci. Technol. 38, 400-408, 2004.

Noone, K. J., Ogren, J. A., Heintzenberg, J., Charlson, R. J., and Covert, D. S.: Design and calibration of a counterflow virtual impactor for sampling of atmospheric fog and cloud droplets, Aerosol Sci. Technol., 8, 235-244, 1988.

Noone, K. B., Noone, K. J., Heintzenberg, J., Ström, J., and Ogren, J. A.: In situ observations of cirrus cloud microphysical properties using the counterflow virtual impactor, J. Atmos. Oceanic Technol., 10, 294-303, 1993.
Novakov, T. and Corrigan, C. E.: Cloud condensation nucleus activity of the organic component of biomass smoke particles, Geophys. Res. Lett., 23, 2141-2144, 1996.

Petzold, A, Ström, J., Ohlsson, S., and Schröder, F.: Elemental composition and morphology of ice-crystal residual particles in cirrus clouds and contrails, Atmos. Res., 49, 21-34, 1998.

Raymond, T. M. and Pandis, S. N.: Cloud activation of singlecomponent organic aerosol particles, J. Geophys. Res., 107, 4787-4798, 2002.

Sassen, K., DeMott, P. J., Prospero, J. M., and Poellot, M. R.: Saharan dust storms and indirect aerosol effects on clouds: CRYSTAL-FACE results, Geophys. Res. Lett., 30, 1633, doi:10.1029/2003GL017371, 2003a.

Sassen, K., Arnott, W. P., Starr, D. O’C., Mace, G. G., Wang, Z., and Poellot, M. R.: Midlatitude Cirrus Clouds Derived from Hurricane Nora: A Case Study with Implications for Ice Crystal Nucleation and Shape, J. Atmos. Sci., 60, 873-891, 2003 b.

Seifert, M., Ström, J., Krejci, R., Minikin, A., Petzold, A., Gayet, J.F., Schumann, U., and Ovarlez, J.: In situ observations of aerosol particles remaining from evaporated cirrus crystals: Comparing clean and polluted air masses, Atmos. Chem. Phys., 3, 10371049, 2003,

SRef-ID: 1680-7324/acp/2003-3-1037.

Ström, J., Strauss, B., Anderson, T., Schröder, F., Heintzenberg, J., and Wendling, P.: In situ observations of the microphysical properties of young cirrus clouds, J. Atmos. Sci., 54, 2542-2553, 1997.

Tabazadeh, A., Jensen, E. J., and Toon, O. B.: A model description for cirrus cloud nucleation from homogeneous freezing of sulfuric acid aerosols, J. Geophys. Res., 102, 23 845-23 850, 1997.

Twohy, C. H., Schanot, A. J., and Cooper, W. A.: Measurement of condensed water content in liquid and ice clouds using an airborne counterflow virtual impactor, J. Atmos. Oceanic Technol., 14, 197-202, 1997.

Twohy, C. H. and Gandrud, B. W.: Electron microscope analysis of residual particles from aircraft contrails, Geophys. Res. Lett., 25, 1359-1362, 1998.

Twohy, C. H., Clement, C. F., Gandrud, B. W., Weinheimer, A. J., Campos, T., Baumgardner, D., Brune, W. H. Faloona, I., Tan, D. Sachse, G. W., and Vay, S. A.: Deep convection as a source of new particles in the midlatitude upper troposphere, J. Geophys. Res., 107, 4560, doi:10.1029/2001JD000323, 2002.

Yin, Y., Carslaw, K. S., and Feingold, G.: Vertical transport and processing of aerosols in a mixed-phase convective cloud and the feedback on cloud development, Q. J. Roy. Met. Soc., 131, 221-245, 2005.

Zhang, Z. and Liu, B. Y. H.: Performance of TSI $3760 \mathrm{CNC}$ at reduced pressures and flow rates, Aer. Sci. Tech., 15, 228-238, 1991.

Zuberi, B., Bertram, A. K., Cassa, C. A., Molina, L. T., and Molina, M. J.: Heterogeneous nucleation of ice in $(\mathrm{NH} 4)_{2} \mathrm{SO}_{4}-\mathrm{H} 2 \mathrm{O}$ particles with mineral dust immersions, Geophys. Res. Lett., 29, 1421-1424, 2002. 